\title{
Real Talk on the Metaphysics of Gender
}

\author{
Robin Dembroff \\ Yale University
}

\begin{abstract}
Gender classifications often are controversial. These controversies typically focus on whether gender classifications align with facts about gender kind membership: Could someone really be nonbinary? Is Chris Mosier (a trans man) really a man? I think this is a bad approach. Consider the possibility of ontological oppression, which arises when social kinds operating in a context unjustly constrain the behaviors, concepts, or affect of certain groups. Gender kinds operating in dominant contexts, I argue, oppress trans and nonbinary persons in this way: they marginalize trans men and women, and exclude nonbinary persons. As a result, facts about membership in dominant gender kinds should not settle gender classification practices.
\end{abstract}

\section{INTRODUCTION}

In 2016, North Carolina embroiled itself in controversy by passing the "Public Facilities Privacy and Security Act." According to this law, someone could not legally enter a men's restroom or locker room unless they were assigned the sex male at birth, nor could they legally enter a women's restroom or locker room 
unless assigned the sex female at birth. ${ }^{1}$ In short, the law insisted that anyone assigned male at birth is a man (or boy), and anyone assigned female at birth is a woman (or girl), effectively refusing social and legal recognition of trans identities. Outcry followed the law's passing, and heated debate over similar legislation-and, indeed, trans identities in general-continues across the United States, the United Kingdom, and other countries. ${ }^{2}$ Such debate often reaches beyond bathroom stalls: for example, under the Trump administration, the Department of Health and Human Services is pushing a "biological, immutable" legal definition of gender, under which an individual's gender is determined by their natal genitalia. ${ }^{3}$

Clearly, gender classifications can be extremely controversial. ${ }^{4}$ Frequently, these controversies manifest as arguments over metaphysical questions, such as who is a man or (woman)? Or what makes someone a man (or woman)? This manifestation seems to rely on the idea that gender classifications should track the gender kind membership facts. Call this the 'Real Gender' assumption. According to this assumption, someone should be classified as a man only if they 'really are' a man - that is, only if man is a recognized gender, and they meet its membership conditions. The same applies for all other gender classifications.

The Real Gender assumption is frequently deployed by those who want to justify dismissals of various gender identities. For example, dismissals of nonbinary identities often are justified using the following logic:

(1) No one is nonbinary (because there are no nonbinary genders).

(2) Someone should be classified as nonbinary only if they really are nonbinary.

(3) So, it is not the case that anyone should be classified as nonbinary.

Premise (2) falls out of the Real Gender assumption: if gender classifications should track gender kind membership facts, then no one should be classified as nonbinary if no one is nonbinary. A similar chain of reasoning is used to justify dismissals of trans men and women's identities, with premise (1) replaced by a premise about the biological features or social experiences that supposedly ground membership in the kinds men or women. For instance, one might think that someone 'really is' a woman only if they were raised as a girl, and that only women should be classified as women.

1. North Carolina State Assembly (2016).

2. According to the National Center for Transgender Equality (2018), 10 states introduced 21 antitrans bills in the first 11 months of 2018. Outside the US as well, debates continue concerning legislation on the mutability of legal gender markers, forced sterilization of trans persons, and trans access to health care, among other things.

3. Green et al. (2018).

4. There are many ways to classify gender. For example, it can occur through verbal attribution directly (e.g., via gender specific pronouns) or indirectly (e.g., referring to someone as 'handsome'). It can occur through behavior directly (e.g., pointing someone toward the men's bathroom) or indirectly (e.g., glaring at someone in the women's bathroom). And it can occur through formal structures directly (e.g., legal gender markers) or through material structures indirectly (e.g., not having tampon dispensers in men's bathrooms). 
From this, they conclude that trans women should not be classified as women. In each case, however, the reasoning vitally relies on the Real Gender assumption.

Common objections to these arguments target the premises (such as premise (1)) that assume gender kinds are trans-exclusive. Opponents respond that there are nonbinary genders, that trans men really are men, and so on. Those who would dismiss trans identities, they claim, get the metaphysical facts about gender kind membership wrong.

In this paper, I suggest that such responses target the wrong premise, and I propose an alternative approach. Rather than insist that gender kinds always are trans-inclusive, I argue that we should reject the idea that gender classifications should track gender kind membership facts-i.e., we should reject the Real Gender assumption. ${ }^{5}$ The gender kinds that operate in a given social context-that is, the gender kinds that are socially salient and meaningful within that contextmay be oppressive. ${ }^{6}$ Genders that ought to be recognized may not be, and there may be recognized genders with unjust membership conditions. Classifying gender solely based on membership in operative gender kinds will reinforce them; if the gender kinds are oppressive, it will reinforce that oppression.

My argument proceeds in four parts. I first motivate the idea of ontological oppression and two of its manifestations: social kinds with oppressive membership conditions, and social contexts that unjustly fail to recognize or construct certain kinds. I then argue that gender oppression of both sorts occurs in dominant contexts: the gender kinds that operate in these contexts marginalize trans men and women, and these contexts exclude nonbinary gender kinds. From here, I argue we have a clear case against the Real Gender assumption. We see that, within dominant contexts, gender classifications should not be constrained by facts about gender kind membership, on pain of reinforcing ontological oppression. In closing, I address worries for and implications of this view.

My argument relies on the assumption that gender kinds are social kinds. To those who think that genders are biological, natural, or otherwise nonsocial kinds,

5. In what follows, I target an assumption that the metaphysics of gender (i.e., the real definition of gender, or of women, etc.) should constrain gender classification practices. Such views seem, to me, more common than the assumption that the semantics of gender (i.e., the correct meaning of 'gender', or of 'women', etc.) should constrain these practices.

6. By 'social context', I mean communities of persons with shared clusters of beliefs, concepts, and attitudes that give rise to concrete social practices and structures. These clusters facilitate social interaction; they make it possible to "interpret and organize information and coordinate action, thought, and affect" (Haslanger 2016, 126). We can specify these communities with various levels of fine-grainedness, relative to the uniformity within shared clusters. I take 'dominant contexts' to be communities that not only hold more social power than other communities, but also impose (often unreflectively) their shared epistemic, conceptual, and affective systems onto less powerful communities. I here draw attention to the fact that social contexts differ with respect to what kinds have social meaning and status. For example, the kind agricultural serf was socially salient and meaningful in the Middle Ages, as it was embedded within economic, class, linguistic, and religious structures. But this kind is not particularly socially meaningful in the contemporary world, except perhaps as an object of historical study or exaggerated (and nerdy) insult. 
this might seem reason to immediately jump ship. But my argument is relevant even for those who hold this view. Even granting, for the sake of argument, that gender kinds are nonsocial kinds, gender classifications clearly have extremely salient and important social meanings. Social roles, expectations, norms, and practices, not to mention self-conceptions, are imposed on people based on their gender classification. Someone who believes that genders are nonsocial kinds should understand my use of 'genders' to pick out kinds of persons who are subject to certain sets of gendered self-conceptions, roles, expectations, norms, and practices due to their gender classification.

\title{
2. ONTOLOGICAL OPPRESSION
}

What is the ontological status of social kinds? Certainly, they are real. Social kinds are embedded in the social world and have immense causal impact on our lives. Even those based on mythical concepts, like witches in seventeenth-century Salem, become political, economic, and personal realities. Moreover, when someone claims membership in a social kind-e.g., "I am disabled" - they typically say something that is not only true, but also often unchosen. We frequently are forced into social kinds regardless of what we, as individuals, might want, say, or think. Consider how gender kinds operate in dominant contexts:

\begin{abstract}
Epistemologically speaking, women know the male world is out there because it hits them in the face. No matter how they think about it, try to think it out of existence or into a different shape, it remains independently real, keeps forcing them into certain molds. No matter what they think or do, they cannot get out of it. It has all the indeterminacy of a bridge abutment hit at sixty miles per hour. ${ }^{7}$
\end{abstract}

In this passage, Catharine MacKinnon describes the mind-independence of a gendered and hierarchical world. While social kinds are 'up to us' in the thin sense that they ontologically depend on social structures and practices, we cannot revise, create, or destroy them through mere desire, thought, or assertion. To revise social kinds, we must revise material structures and practices. ${ }^{8}$ Concepts are not enough; social kinds are not in the head. If we want to analyze the metaphysics of a social kind, or see whether a certain kind operates in a social context, we must look to the relevant structures and practices in that context. ${ }^{9}$ What people say or think

7. MacKinnon (1989), 123.

8. This view is clearly defended in Haslanger (2007) and (2016), and also is presupposed in a variety of sociological and historical literature, such as Molina (2014).

9. See Haslanger (forthcoming), 14: "We might debate about: who is, or is not, a woman or man; whether some people are both women and men; whether some people are neither women nor men; whether one's being a woman or man depends on context, etc. On my view . . in attempting to answer them we are theorizing about the world. We should, I believe, draw on biological, 
about a social kind can come apart from the metaphysical facts about that kind: often, we are too embedded in our spaces, legal systems, beliefs, and habits to clearly see the social kinds they construct. ${ }^{10}$ Gender kinds, for example, are discovered by looking to (e.g.) the gendered language, legal and family structures, labor divisions, stereotypes, merchandise, and sexual expectations and practices within a context-evidence often underappreciated within popular beliefs about gender.

Consider another example: the kind athlete. It is common to think that exemplar members of this kind-those with marked athletic success-are those with innate athletic abilities. ${ }^{11}$ But this is far from the case. Closer examination of the structures and practices surrounding sport reveals that the existence and membership conditions of this kind are, rather, sensitive not only to extensive training and nutrition practices, but also to complex and often sexist, classist, and ableist assumptions about what counts as athletic skill and what counts as sport. ${ }^{12}$ As a result, the boundaries around the kind athlete-i.e., the social rules that police membership in this kind-historically have been and continue to unjustly and systematically exclude certain groups (e.g., women, people from working-class backgrounds, people with disabilities). Moreover, certain kinds have, as a result of the same structures and practices, failed to operate in social contexts: in the late nineteenth and early twentieth century, women often were barred-both by social stigma and official rules-from athletic competitions. ${ }^{13}$ Similarly, it was not until recently that disability sport was an operative kind in dominant contexts, or that trans athlete or gay athlete were possible social identities, much less identities available to professionally successful athletes.

This example illustrates two more general claims, which are, I hope, fairly intuitive:

(1) Operative social kinds can have unjust membership conditions, and

(2) The structures and practices within a social context can unjustly fail to recognize or construct certain kinds.

historical, anthropological, sociological, psychological, and normative inquiry (including feminist theory and queer theory) to answer the questions."

10. This point has been well recognized in the feminist metaphysics literature. Haslanger (1995) uses the terms 'manifest' versus 'operative' concepts to mark this distinction.

11. The success of David Epstein's 2014 book The Sports Gene, as well as the rising trend of DNA testing for sports capacities speaks to the prominence of this idea.

12. See, e.g., Eckstein et al. (2010), who argue that the "athletic-industrial complex" is "an institutional conduit of economic and political inequality" (501).

13. This is not to say that there was no women's sport, or that women did not participate in sporting events, but rather that their participation was often considered leisure and not competitive, as the aggressiveness required for competitive sport created a role violation for many women, and one typically not tolerated by men. Moreover, even this was hugely inflected by class: as Guttman (1991) points out, "In the 1890's, while medical experts debated whether or not strenuous exercises endangered a middle-class girl's capacity to conceive and bear children, working-class women were competing in six-day bicycle races." 
Claim (1) points to cases where the boundaries around a social kind are set up such that groups who ought to have access to kind membership (or to exit membership) do not or rarely have such access. ${ }^{14}$ The kind eligible voter provides a clear example. Historically, this kind had membership conditions that unjustly excluded anyone assigned female at birth; today, in many US states it has conditions that unjustly exclude persons with criminal records.

Claim (2) points to cases where, due to historical or continued prejudice, the social practices and structures in a context unjustly fail to recognize or construct a certain kind. I say "recognize or construct" because this occurs both when social structures and practices fail to integrate already existing kinds, as well as when they unjustly fail to construct new kinds. An example of the first sort is doctors' historical failure to recognize medical conditions that primarily affect women, such as endometriosis. The condition of endometriosis existed prior to social recognition. But it was unjust that this condition was not recognized within social practices-it did not have associated social meaning or bodies of knowledge. Examples of the second sort include lawmakers' historical (and, in some contexts, continued) failure to construct the kinds same-sex marriage or minimum wage. ${ }^{15}$

Both claims (1) and (2) point to particular manifestations of a larger phenomenon I call ontological oppression, which occurs when the social kinds (or the lack thereof) unjustly constrain (or enable) persons' behaviors, concepts, or affect due to their group membership. ${ }^{16}$ While ontological oppression can manifest in many ways, for present purposes, I am interested in these two ways: namely, where membership conditions or ontological lacunas create these unjust constraints (or enablements). ${ }^{17}$

The two manifestations often are sides of the same coin. Consider heterosexist membership conditions for marriage: i.e., restrictions that only allow marriage between someone legally recognized as male and someone legally recognized as female. A context with these conditions could also be described as unjustly failing to construct the kinds same-sex marriage or polyamorous marriage. In fact, the explanation for why marriage has unjust membership conditions is the same as the explanation for why these other kinds unjustly are not constructed..$^{18}$ Both expla-

14. Another way to describe this is as grounds for kind membership that unjustly constrain access to the social standing and recognition that accompanies membership. This is distinct-though importantly connected-to the question of whether injustice causally entered into the process by which a kind or its membership conditions were constructed.

15. In the US, these failures perpetuated until 2015 and 1938, respectively.

16. Within this, I include access to social goods such as healthcare (as in the case of endometriosis). Dembroff (2017) explores the idea of ontological oppression more thoroughly-here, I focus only on a portion of the idea relevant for present purposes. See also Jenkins (2016) for exploration of a similar idea.

17. Another way ontological oppression manifests is when the social meaning of kind membership is unjust. Frequently, this leads to wrongful treatment of kind members-racism, ableism, transphobia, and other prejudices are indicative of this type of ontological oppression.

18. This is not to suggest that marriage would be a just institution with these adaptations-see Chambers (2017). 
nations come back to the social structures and practices within that context-ones that fail to legally recognize queer and polyamorous relationships. The difference here is one of emphasis: namely, whether the relevant injustice is best described as the failure to allow queer and polyamorous persons into an existing social kind, or as the failure to construct new social kinds that explicitly recognize these relationships.

Because kinds like marriage and eligible voter have (at least largely) legally codified membership conditions, these are easy places to identify ontological oppression. The history (including contemporary history) of these kinds is fraught with membership conditions designed to reinforce the same sexist, racist, ableist, and xenophobic contexts that first constructed them. That is, in short, oppressive social contexts generate social kinds that reinforce those contexts. A patriarchal context that bars women from the kind eligible voter thereby constructs eligible voter in a way that perpetuates patriarchal control. A heterosexist state that fails to recognize queer and polyamorous relationships constructs marriage, civil union, legal guardian, and other related kinds in ways that perpetuate its heterosexist structures. And so on.

We see the same pattern in oppressive contexts where certain identities are unrecognized or unavailable. Consider the long struggle against what has come to be known as "bisexual erasure," or the systematic misrecognition of bisexual identity. This misrecognition is a global phenomenon and has been well documented across both legal and nonlegal contexts. ${ }^{19}$ Due to pervasive protection of heteronormativity, and the corresponding policing of masculinity and erasure of female sexuality, bisexual men frequently are classified as gay, and bisexual women as straight, despite their protests to the contrary. This is an example of ontological oppression, not because gay and straight-i.e., the operative sexual orientation kinds-have unjust membership conditions, but because social structures and practices fail to recognize the kind bisexual.

These examples illustrate the two aforementioned types of ontological oppression. Further examples could draw from many other social kinds, such as philosopher, parent, or disabled, not to mention various racial, class, caste, economic, religious, and scientific kinds. ${ }^{20}$ Unjust social structures and practices abound. So too, then, do examples of social kinds (or the lack thereof) that have unjustly constrained (or enabled) groups of people.

At this point, we are positioned to criticize a generic version of the Real Gender assumption:

19. See, e.g., Marcus (2018) and Yoshino (2000), among many others.

20. For example, in the 1950s and 1960s in the United States, gays and lesbians were not recognized as parents, even of their own biological offspring. See Rivers (2015), 31: "Being a lesbian or a gay man was widely understood [in the 1950s and 1960s US] as antithetical to parenting; the threat of losing custody of their children kept many men and women from leaving heterosexual marriages and enforced the silence and invisibility of those who did raise children in same-sex households." 
Social kind classifications ought to track the operative social kind membership facts.

This generic version tells us that social classifications should be conditioned on whether the target kind operates in one's social context, and its membership conditions are met. Here, the assumption purports to be innocently truth-tracking: it appears to merely ensure that a community's classifications faithfully tracks the social kinds that operate in their community.

This might seem tempting. In general, we want classification practices to be truth-tracking. It is disastrous when chefs treat plants as edible that are poisonous, or when licensing boards treat persons as doctors who lack the relevant competencies. Similarly, constraining classifications to accurately track social kind memberships is fundamental to social coordination. ${ }^{21}$ It is not unreasonable to want our concepts, linguistic and legal markers, and material spaces to faithfully track these memberships. Moreover, this assumption provides what might seem to be reasonable constraints on when an individual can demand that their self-identification, or what they take themselves to be, become a social identification, or what others recognize them as being. ${ }^{22}$ It says that, if someone's self-identification is unintelligible in a social context, it need not be recognized. The same applies for selfidentifications that, while perhaps intelligible, conflict with an operative kind's membership conditions. For these reasons, we can ignore someone who claims to be a Viking, or someone who is very wealthy but claims to be middle class.

Despite this apparent innocence, the generic assumption ignores the possibility of ontological oppression. ${ }^{23}$ Assuming that social kinds can have unjust membership conditions, or that the structures and practices in a context can unjustly fail to recognize or construct certain kinds, constraining classifications to track operative social kinds would be ill advised. It would perpetuate unjust kinds, or the unjust exclusion of certain kinds, rather than adapt social practices to newly construct, revise, or eliminate operative social kinds. In short, the assumption is a mechanism for maintaining the ontological status quo. It fails to account for what Ian Hacking, Ron Mallon, and others call the "looping effect" between classification practices and social kinds. ${ }^{24}$ This looping effect, in brief, is the mutual causal feedback between classification practices and what social kinds exist: by developing classification practices, we create social kinds, which in turn impact classification practices, and so on. The looping effect, as Mallon describes it, means that "human

21. See O’Connor (2019).

22. That is, constraints on uptake of 'agential identity'. See Dembroff and Saint-Croix (forthcoming).

23. As Joanna Lawson pointed out to me, the generic assumption is untenable for a broader reason: it forecloses the possibility that we should, for any reason, create new social kinds or revise existing social kinds. Here I focus on moral reasons for changing or revising social kinds, but we can imagine cases where other sorts of reasons, e.g., pragmatic or epistemic reasons, are more relevant.

24. See Mallon (2016) and Hacking (1999). Hacking is primarily focused on scientific classifications, but the framework can be applied more broadly. 
[kinds] themselves are . . . in some way a product of a community's practices of labeling and differentially treating [kind] members." ${ }^{25}$ Mallon's insight concisely reveals why classification practices should stray from the operative social kinds under conditions of ontological oppression. Unless they do so, they will reinforce that oppression.

\section{ONTOLOGICAL GENDER OPPRESSION}

In this section, I take the notion of ontological oppression and apply it to gender kinds. I argue that the Real Gender assumption guides many disputes over gender classification, and also that we have reason to think that the operative gender kinds within dominant contexts are oppressive. As a result, we have good reason to reject the Real Gender assumption. Even the most accurate analysis of these gender kinds will not settle what gender classification practices should be. In closing, I'll gesture toward ameliorative approaches to ontological gender oppression, in lieu of the Real Gender assumption.

\subsection{THE REAL GENDER ASSUMPTION}

Let's spell out the Real Gender assumption:

Gender classifications should track the operative gender kind membership facts.

The prominence of this assumption is difficult to overstate. Consider the rhetoric surrounding disputes over gender recognition with respect to public spaces, such as the North Carolina "Public Facilities Privacy and Security Act" or the U.K.'s "Gender Recognition Act." In these contexts, social conservatives who reject trans identities typically base their position on a genital-based understanding of gender kinds, which says that one's gender is based on one's natal genitalia. ${ }^{26}$ They then deploy the Real Gender assumption: gender classifications therefore should track (genital-based) gender kind membership. We can see this move in rhetoric employed by opponents of a city ordinance in Charlotte, North Carolina, that (among other things) forbid discrimination on the basis of gender identity:

"A few, short years ago, you ... would have laughed at the idea of a man showering in a locker room with your daughter."27

25. Mallon (2016), 1. Mallon uses 'categories' but I use 'kinds' in order to avoid connotations of mere linguistic construction.

26. Sometimes the position is based on a 'socialization' view of gender, on which one's childhood socialization determines one's gender. Since this socialization is based upon natal genitalia, though, the extensions of the two views are nearly identical.

27. "Charlotte City Council approves LGBT protections in 7-4 vote" (2016). 
"Keeping separate facilities validates the uniqueness of each gender. Male and female were created distinctly to fulfill vital roles in our society. [We must] protect the safety and sanctity of our men, women ... boys, and girls."28

"White woman identifies as Black ... Man identifies as woman ... We're going to throw out science and DNA?"29

While tortured, these statements circle around a similar logic:

(a) One's natal genitalia determine one's gender.

(b) Gender classifications should map the gender kind membership facts.

(c) Therefore, trans persons should be classified according to their natal genitalia.

In this line of reasoning, (b) assumes a particular connection between the gender kind membership facts and what gender classification practices should be. But, as mentioned previously, rather than question this assumption, progressives by and large focus on challenging (a). That is, their efforts take (b) for granted, and target the claim that gender kind membership (even in dominant contexts) is determined by natal genitalia. This focus is apparent in recent literature on the metaphysics of gender, where philosophers employ the following sort of argumentative schema:

1. Persons in Group X are men.

2. Theory $\mathrm{T}$ implies that persons in Group $\mathrm{X}$ aren't men.

3. Therefore, we should reject Theory $\mathrm{T}$.

For example, one version of this schema would go as follows:

i. Trans men are men.

ii. Position-based theories of gender imply that some trans men aren't men. ${ }^{30}$

iii. Therefore, we should reject position-based theories of gender. ${ }^{31}$

The schema, on the surface, seems to provide a powerful tool against particular theories of gender. Counterexamples are, after all, a regular feature of argumentation. But claims taking the form of (1) often appear insensitive to the highly contextual nature of operative gender kinds. Once we build in that sensitivity, it suggests that these arguments draw upon intuitions that build a schema more like the following:

\footnotetext{
28. Ibid.

29. Ibid.

30. Namely, trans men who are not perceived as men.

31. For an example of this argumentative move, see McKitrick (2015).
} 
$1^{*}$. Persons in Group $\mathrm{X}$ should be classified as men in dominant contexts.

2. Theory $\mathrm{T}$ implies that persons in Group $\mathrm{X}$ aren't men within dominant contexts.

3. Therefore, we should reject Theory $\mathrm{T}$.

This schema prescribes a certain gender classification practice, and then evaluates a theory of gender kinds based on whether gender kind membership according to that theory align with the prescribed classification practice. But this move again seems to rely on the assumption that gender kind membership should constrain gender classification-i.e., the Real Gender assumption. On this way of thinking, an accurate theory of gender will reveal answers to questions such as, "Should we use male-coded language (e.g., 'son', 'sir') to refer to a trans man?" Or "Should the federal government recognize nonbinary genders?" For this reason, a theory that describes trans-exclusive gender kinds often is rejected not only for implying that trans-identity claims are false, but also that gender classifications need not be transinclusive. ${ }^{32}$ (I argue in section 3.3 that a theory of gender need not do either.)

Here, I agree with Elizabeth Barnes, who notes that on most accounts of gender, facts about gender kind membership are taken to underlie facts about which gender classifications are unjust:

A successful account of gender ought to say that trans women are women; it would be unjust not to classify trans women as women. But at least part of that injustice, on most accounts, consists in failing to treat trans women as what they are. That is, it's unjust to say that trans women aren't women because trans women really are women. ${ }^{33}$

Barnes here observes that, on most accounts, the fact that gender classifications should be trans-inclusive is taken to be explained by facts about gender kind membership..$^{34}$ But notice that this entails the Real Gender assumption. To take facts about kind membership to explain facts about just and unjust classification just is to take the former facts to constrain the latter facts, such that only those who are, say, men have claim to classification as men.

Sometimes this assumption is implicit. Jennifer McKitrick (2015), for example, rejects position-based theories on gender on the ground that they have "problematic implications for transgender." ${ }^{35}$ But sometimes it is more explicit. Mari Mikkola (2016) argues that theories of gender ought to be constrained by the gender classifications that trans persons want:

32. For sake of clarity, I somewhat begrudgingly use the term 'trans-inclusive', even though trans persons are not merely included within operative gender kinds in trans-friendly contexts, but are paradigmatic members of these kinds.

33. Barnes (2016).

34. There are important exceptions, most notably the work of Talia Bettcher $(2009,2013,2014)$, Ásta (2011), and Jenkins (2016).

35. McKitrick (2015). 
Theory of gender that point-blank excludes trans ${ }^{\star}$ women from women's social kind is simply unacceptable. But just as I find it politically problematic to propose such an exclusionary theory, I find it problematic to propose a view that unquestionably includes trans ${ }^{\star}$ women. After all, not all trans ${ }^{\star}$ women want to be part of women's social kind ... Some want to be identified specifically as trans ${ }^{*}$ women rather than women... Political concerns are critical when deciding how to proceed. ${ }^{36}$

Mikkola suggests that we prefer theories of gender that align with certain political commitments regarding gender classification. ${ }^{37}$ Trans identities deserve to be respected in our classifications, so theories of gender should be sensitive to these identities and avoid implying that trans identities do not track the relevant gender kinds. But here again, we find the Real Gender assumption. Without this assumption, it is unclear why we should ensure that theories of gender align with what we take to be just gender classification practices.

Ontological oppression exposes the flaw with the Real Gender assumption: it presupposes that the gender kinds operating in one's context are not deeply distorted and unjust. This presupposition is not justified.

Why, then, do we frequently appeal to this assumption? The primary reason, I think, is a tendency to ignore the contextual nature and plurality of gender kinds while remaining committed to the idea that trans and queer identities track real gender kinds. But we cannot have it both ways: commitment to gender constructionism pushes us to give up the mirage that one set of gender kinds operates in all contexts. On a constructionist picture, material structures and social practices construct gender kinds: structures and practices that vary across contexts. In short, it implies pluralism about operative gender kinds. ${ }^{38}$ And while I cannot fully defend gender pluralism here, it's noteworthy that context-sensitive gender theorizing is standard practice within other humanities and the social sciences. There is overwhelming evidence that gender structures and practices vary across place and time, and are constructed in tandem with race, religion, class, ability, and other social identities. This gives us excellent reason to think that operative gender kinds differ in drastic and important ways across contexts: the gender kinds that operate in dominant Western contexts may differ from those that operate in Indigenous contexts, trans and queer contexts, historical contexts, etc.

When we take this pluralism seriously, we see the possibility that operative gender kind in dominant contexts (herafter 'dominant gender kinds') differ from those within communities of color, or within queer, working-class, or disabled

36. Mikkola (2016), 114-15.

37. In fact, this constraint on a metaphysical analysis of gender has become so widespread that it is known as the "commonality constraint," and is also found in Bach (2012), Tiechman (manuscript), and McKitrick (2015)

38. Pluralism is not deflationism about gender kinds. Nor do pluralists, like Elizabeth Spelman and others, take intersectional considerations to reveal futility in metaphysical theorizing about gender. Gender pluralism, as I am thinking about it, is the view that there are many gender kinds, only some of which operate in a given context. 
communities, as well as their many intersections. My focus in what follows is on a particular way these kinds differ. Specifically, I argue that dominant gender kinds marginalize trans men and women, and do not include nonbinary kinds. Given this, I'll argue that those who take trans inclusion within dominant contexts to be a worthy political goal have good reason to reject the Real Gender assumption. ${ }^{39}$ Instead, I'll suggest that they should work to import the gender kinds that operate in trans and queer communities.

\subsection{DOMINANT GENDER KINDS}

We've seen the Real Gender assumption appear in popular and philosophical discourse surrounding gender classifications. We've also seen that the possibility of ontological oppression undermines this assumption. That is, seeing that social kinds can be oppressive undermines the idea that we should rely on them to determine classification practices. Here, I argue that dominant gender kinds are oppressive, focusing on trans and nonbinary persons in particular. ${ }^{40}$

I won't provide a complete defense for this claim: many books and articles have outlined in detail the material spaces, conceptual lacunas, legal and economic practices, derogatory language, medical barriers, and other social systems that regularly marginalize or erase trans and nonbinary identities. My goal is simply to point to evidence that dominant gender kinds marginalize trans women and men and exclude nonbinary kinds. If true, dominant gender kinds arise from and reinforce oppressive social systems-i.e., they reveal ontological oppression of both previously discussed varieties. But in that case, those in dominant contexts should not base gender classifications on these kinds.

Let's first consider the claim that dominant gender kinds have unjust membership conditions - in particular, ones that marginalize trans women and men. To see why this is true, one need only look to the structures and practices that rely on natal genitalia, or secondary sex characteristics and aesthetics taken to indicate natal genitalia, to determine persons' genders. As MacKinnon succinctly puts this point, "Male dominant society has defined women as a discrete biological group forever." ${ }^{41}$ While trans identities have garnered some social and legal recognition in progressive circles, it remains the case that default gender designations (via assigned sex at birth) are based on natal genitalia, and also that trans persons

39. I hedge here because I don't assume that trans inclusion within dominant contexts is a valuable political goal. Much depends, to my mind, on how successfully queer and trans practices can be truly adopted, rather than modified so as to assimilate queer and trans persons into dominant culture. For queer critiques of such assimilation, see Stone (1992), Bornstein (1994), and Spade (2015), among others. See section 3.3 for further discussion.

40. I agree with Bettcher (2013), 243, that part of what explains this ontological oppression are false beliefs-specifically, in my view, false beliefs about determined or 'natural' connections between biological features, psychological features, and social roles.

41. Williams (2015), interviewing MacKinnon. 
are far from achieving acceptance that is not conditional on their assimilating to cisnormative bodily presentations.

Within the United States, for example, some states do not allow trans persons to change their legal gender markers. Many more have draconian rules for doing so, including required surgeries or other medical treatments that, even if desired, are often economically inaccessible to trans persons, who are more likely to be unemployed and uninsured. ${ }^{42}$ Moreover, both inside and outside legal structuresand particularly in the criminal justice system and prison industrial complexthere is constant and systematic discrimination against trans people, and especially those who are visibly trans. ${ }^{43}$ These facts get increasingly worse when we consider intersectional identities: trans women, and especially trans women of color, are most likely to experience fatal violence, unemployment, domestic abuse, harassment, and a lack of access to medical care ${ }^{44}$ Looking directly at dominant gender kinds, we can see that, to quote Talia Bettcher, "a trans [woman] would be-at most-legitimized as a (marginal) woman through somehow arguing that she meets enough of the dominant criteria of membership." ${ }^{45}$ Within these contexts, Bettcher points out, trans-identity claims are either unjustified or justified only to the extent that these identities are intelligible according to "dominant criteria of membership." ${ }^{6}$ The bar for justification is raised when trans identities intersect with other marginalized identities. ${ }^{47}$

A distinct but related form of oppression concerns those who claim nonbinary identities - that is, those who do not identify exclusively as men or women. Within dominant contexts, there is even less recognition of nonbinary identities than trans-binary identities. ${ }^{48}$ In the United States as of 2018, every state requires binary gender markers to be assigned at birth, and only four states and Washington, DC, allow persons to later select a nonbinary gender marker. Those who are able to get nonbinary gender markers struggle to obtain passports and other legal documentation..$^{49}$ As with trans men and women, this lack of recognition extends into

42. National Center for Transgender Equality (2016).

43. Ibid. Almost one-third of trans people live in poverty and are twice as likely to be unemployed, one-fourth have avoided medical care from fear or harassment, and half experience intimate partner violence. See also Stanley and Smith (2011) and Knight and Wilson (2016) for transcentered critiques of the criminal justice system and the prison industrial complex.

44. National Center for Transgender Equality (2016).

45. Bettcher (2013), 246. The original quote read "trans person."

46. Ibid.

47. See, e.g., Koyama (2006), which examines how trans women of color, and in particular those from working-class backgrounds, are systematically excluded from white feminist spaces. See also Roen (2001), which discusses how some trans persons of color resist contemporary western trans medical practices in order to retain cultural values, making it difficult for them to achieve uptake of their identities, including within queer theorizing.

48. By 'trans binary identities', I mean trans male and trans female identities.

49. The international legal landscape also is complex. As of 2018, Canada, India, and Australia have voluntary third gender markers, and a few other countries mandate third gender markers for persons with intersex conditions, or at least allow such persons to claim a third gender marker. 
medical, workplace, educational, and other social domains. Within these domains, nonbinary identities often are not only ignored, but unintelligible. Once again, this system of misrecognition is generated by the structures and practices that construct and define dominant gender kinds. These facts suggest that, within most dominant contexts, nonbinary gender kinds simply do not appear. While nonbinary identities are recognized within trans-inclusive communities, these identities have no home within dominant contexts, where everyone is forced into one of two binary kinds (men and women).

There are many injustices that arise from this exclusion. One in particular is nicely captured by Naomi Scheman's work on heteronormativity, and the limitations it places on the 'narratives' or social scripts that we use for making ourselves intelligible to ourselves and to others. "Narrativity per se may be humanly important," Scheman writes, "but we have no access to narrativity per se: What we have are culturally specific narratives, which facilitate the smooth telling of some lives and straitjacket, distort, or fracture others. ${ }^{\prime 50}$ Intelligibility often is inaccessible to queer and trans subjects within dominant contexts, where their identities have no location within the operative gender kinds. And while this certainly applies to both nonbinary and trans-binary subjects, the complete failure to recognize nonbinary gender kinds within dominant contexts makes the intelligibility problem especially salient for nonbinary persons.

Again, I haven't presented a comprehensive picture of how dominant gender kinds marginalize and erase trans and nonbinary identities. Any such argument would span multiple books and draw from philosophical, historical, legal, sociological, anthropological, political, and other sources of information. ${ }^{51}$ Happily, other scholars collectively already have done this detailed work. My goal is simply to draw attention to the fact that, within dominant contexts, "we [trans people] are systematically constructed in ways that run contrary to our own self-identifications." ${ }^{\text {. As }}$ a result, dominant gender kinds systematically oppress persons who claim trans and nonbinary identities. They do not reveal what gender classification practices should be; they reveal what these practices have been.

\subsection{BEYOND THE 'REAL GENDER' ASSUMPTION}

I've argued that we should not employ the Real Gender assumption, on pain of reinforcing oppressive gender kinds. My argument, as it applies to dominant contexts in particular, can be summarized as follows: ${ }^{53}$

1. The Real Gender assumption should not guide gender classifications in contexts where the operative gender kinds are oppressive.

50. Scheman (2011), 113-14.

51. See, e.g., Bornstein (1994), Risman (2018), Clark (2019), Stryker (2008), among many more.

52. Bettcher (2007), 69.

53. I take my claim to undercut the Real Gender assumption in all contexts, but here focus on dominant ones. 
2. Dominant gender kinds oppress trans and nonbinary persons.

3. So, the Real Gender assumption should not guide gender classifications in dominant contexts.

In dominant contexts, it is wrongheaded to determine gender classifications by looking to operative gender kinds. But how, then, should they be decided? What should guide gender classifications?

On a bootstrapping approach, classification practices might be based on what, according to our best normative theory, seems to accommodate the interests of gender justice. This approach would begin with a series of difficult questions such as 'How much autonomy should someone have over their gender kind membership?' 'Which gender kinds should we recognize?' Or 'How can we balance an interest in gender autonomy with an interest in social coordination?' Classification practices could then be devised based upon answers to these questions.

This approach, perhaps appealing to theorists, poses serious practical worries. Making it workable requires coordination and agreement on a range of complex normative issues, as well as in devising and implementing new classification practices. While not impossible, there is a more feasible approach. On this different approach-the 'imitation' approach—classification practices can be revised based upon those that already exist within other communities. Given that operative gender kinds vary across contexts, looking at other communities will reveal alternative gender kinds and corresponding classification practices. From here, those in one context can attempt to revise their operative gender kinds by mirroring or otherwise imitating the structures and practices that already exist in other contexts. ${ }^{54}$

To improve dominant gender kinds, trans-inclusive and queer communities are obvious places to begin. The operative gender kinds in these contexts are markedly different from those in dominant contexts. For one, within these communities, nonbinary gender identities have intelligible social meaning because of systems that accommodate these identities. For example, these communities have developed systems of gender-neutral language, gender-neutral physical spaces, practices of attention to chosen names and pronouns, and increased freedom within gender expression and gender roles. ${ }^{55}$ Collectively, these structures and practices create intelligible social space for those who claim nonbinary identities: that is, they construct nonbinary gender kinds. ${ }^{56}$

Similarly, within these communities, membership criteria for men and women differ from the corresponding criteria in dominant contexts. Genitalia-much less natal genitalia-does not determine gender classification. Individuals are granted

\footnotetext{
54. For example, consider the Swedish decisions to import (with some alteration) the Finnish genderneutral pronoun ' $h a ̈ n$ ', rather than invent a neologism

55. For empirical research and first-personal accounts of these structures and practices, see, e.g., Risman (2018), Bradford et al. (2018), and Nestle et al. (2012).

56. Dembroff (manuscript).
} 
authority over their gender kind membership. They also are given - to some extentauthority over the social significance of this membership:

In [trans-inclusive communities], the authority of transsubjects in determining self-identity is generally taken as a starting point, and the significance of the gender presentation as well as gender identification category is generally provided by the subjects own personal 'intelligibility conferring' narrative. ${ }^{57}$

In trans-inclusive contexts, in other words, individual autonomy over both gender kind membership and the meaning of that membership is presupposed. Gender classification practices in such communities defer to self-identification, and do not take anatomical information or gender presentation to determine gender. Not only is someone's claim to be (e.g.) a woman taken as authoritative, so too are her claims about what this identity signifies about herself and how she would like others to interpret this claim.

Again, I've given nowhere near an exhaustive analysis of trans and queer gender kinds. They are legion, and can be treated with evermore fine-grained contextual and intersectional analysis. But I hope to have said enough to motivate the idea that those in dominant contexts are not constrained to either rely on the Real Gender assumption or attempt to build new gender kinds from the ground up. Trans-inclusive gender kinds have rich histories within trans and queer communities: why reinvent the wheel when it is spinning and fabulous?

With that said, the idea of bringing trans-inclusive gender kinds into dominant contexts raises serious challenges. One obvious challenge is whether trans and nonbinary gender kinds could be incorporated within dominant structures (such as legal systems and educational, corporate, and religious institutions) without being destroyed. Are these kinds doomed to become distorted when integrated into dominant contexts? Queer theorists have been almost uniformly skeptical that this distortion could be avoided:

What is gained is acceptability in society. What is lost in the ability to authentically represent the complexities and ambiguities of lived experience ... To attempt to occupy a place ... within the traditional gender frame is to become complicit in the discourse that one wishes to deconstruct. ${ }^{58}$

Sandy Stone here articulates the worry that dominant gender systems are simply incapable of recognizing trans and nonbinary identities. These systems inevitably reduce such identities. In particular, they destroy the "complexities and ambiguities" that are central to trans and nonbinary identities, and impose conformity onto them-a conformity that is necessary for state, economic, and social control over gender. Such control is, according to Stone (and I agree), characteristic of dominant contexts.

57. Bettcher (2007), 59.

58. Stone (1992), 164-65. 
I sympathize with these worries. But for two reasons, I do not take them to undermine all attempts to make dominant gender kinds more trans and nonbinary inclusive. Nor do they undermine arguments against the Real Gender assumption.

First, I think these concerns are tempered by the deconstructive potential of trans and queer identities once brought into dominant contexts. Could dominant gender systems continue to function as they currently do once they incorporate trans and nonbinary gender kinds? I agree with Stone that these systems, as they currently stand, are incompatible with such identities. But why assume the latter, rather than the former, will be broken down? Trans-hostile people recognize this alternative possibility: If gender becomes based on self-identification, they worry, the social systems that smoothly determine social expectations, family structures, sexual availability, and gender-based labor divisions will become muddied and inefficient. ${ }^{59}$ Here, to my mind, one man's modus tollens is one queer's modus ponens.

Second, I agree with many queer theorists that oppressive, trans-hostile, and heterosexist social structures produce (and have produced) vibrant communities committed to alternative gender possibilities. ${ }^{60}$ These communities are extremely valuable. But does that mean we should preserve trans-hostile and heterosexist social structures? Revising dominant gender kinds isn't an 'all or none' situation: any degree of assimilation may be to some extent destructive of trans and nonbinary gender kinds. But also destructive are the effects of trans and nonbinary misrecognition, including police violence, marginalization, incarceration, unemployment, homelessness, domestic abuse, and suicide. In the end, we may find that there is no true middle ground between destructive oppression and destructive assimilation. But I think working to find one is preferable to the status quo, particularly given the number of trans and nonbinary persons who sincerely desire gender classifications, within dominant contexts, that align with their self-identities. ${ }^{61}$

\section{WORRIES AND UPSHOTS}

Using dominant contexts as my central case, I've argued for scrapping the Real Gender assumption. I’ve also suggested an 'imitation' strategy for revising dominant gender kinds. I now turn to worries for and upshots of this view.

\subsection{ARE TRANS AND NONBINARY GENDER IDENTITIES NONVERIDICAL?}

One might worry that, if I am right that dominant gender kinds marginalize and exclude trans and nonbinary persons, then trans and nonbinary identities are

59. Thanks to Katharine Jenkins for raising this point.

60. See Foucault (1978) on power and productivity.

61. I assume a prima facie obligation to respect individuals' request for social recognition of their self-identities. See McQueen (2016) for a critique of "post-identity" queer politics. 
nonveridical. That is, because trans and nonbinary gender kinds do not operate in dominant contexts, one might worry that trans and nonbinary identities do not reflect actual gender kind memberships. Moreover, one might think, feminist theorizing should provide theories of gender such that trans identities always are veridical.

I think this criticism comes from a mindset according to which metaphysicians are restricted to the following options:

1) Privilege Dominant Contexts: Dominant gender kinds are the only gender kinds. Gender identities are veridical when they track these kinds.

or

2) Privilege Trans Contexts: Trans-inclusive gender kinds are the only gender kinds. Gender identities are veridical when they track these kinds.

This is a false dichotomy. Again, because gender kinds are socially constructed, we should expect operative gender kinds vary across contexts. While trans and nonbinary identities may not align with dominant gender kinds, this does not mean that they are nonveridical. At most, it would mean that they are nonveridical in dominant contexts and veridical in trans-inclusive contexts.

I say 'at most' because we need not even accept this. Trans and nonbinary identities could both fail to align with dominant gender kinds and remain veridical even within dominant contexts. This is because one's gender kind memberships are indexed to various gender kinds, only some of which operate in one's immediate context. Someone's identity, then, may be based on membership in a kind that is not operative in their immediate context.

To illustrate, consider the following passage, which addresses a similar scenario with respect to race:

Some men who are black in New Orleans now would have been octoroons there some years ago or would be white in Brazil today. Socrates had no race in ancient Athens, though he would be a white man in Minnesota. ${ }^{62}$

At first pass, this text suggests that some persons who are black in New Orleans today, if transported to Brazil, would no longer be black. They would speak falsely if they said, in Brazil, "I am black." After all, one might think, if we are going to accept that race is socially constructed, then operative racial kinds vary across contexts. But if operative kinds vary across contexts, then one's race also seems to vary across contexts. Similarly, one might think, for gender. Accepting-as I've argued - that operative gender kinds vary across contexts, then some persons who are men in trans-inclusive contexts are not men in dominant contexts. On this

62. Root (2000, S631-32), cited in Mallon (2004). 
reading, a trans man's identity becomes nonveridical in dominant contexts. $\mathrm{He}$ speaks falsely if he says in this context, "I am a man."

Despite the intuitive pull of this idea, it is one we have good reason to deny. Pluralism about operative gender kinds is compatible with the claim that a trans man's identity is veridical in all contexts. And this means it is compatible with the idea that when he says, "I am a man," he picks out a true proposition regardless of the context of utterance.

To see why, we can follow Joshua Glasgow in distinguishing between 'modest' and 'extreme' ontological pluralism. ${ }^{63}$ On modest ontological pluralism about gender, someone simultaneously has multiple genders, relative to different gender kinds. ${ }^{64}$ However, the salience and relevance of a given gender differs across contexts, because contexts differ in their operative gender kinds. For example, relative to dominant contexts, someone's classification based on natal genitalia may be most salient and relevant, even though they simultaneously belong to distinct gender kinds that operate in trans-inclusive contexts. On extreme ontological pluralism about gender, in contrast, someone only has one gender kind membership at a given time, and this membership depends on the operative gender kinds in one's immediate context. That is, for example, as one moves from a dominant to a trans-inclusive context, their gender might change from woman (relative to the dominant kind) to man (relative to the trans-inclusive kind).

This distinction reveals two additional options for metaphysicians:

3) Adopt extreme ontological pluralism: One's gender kind membership changes across contexts.

or

4) Adopt modest ontological pluralism: One is a member of many gender kinds, but the social relevance of these memberships change across contexts. ${ }^{65}$

Pluralism rules out a single set of operative gender kinds. But it leaves open a further question: do our gender kind memberships change across contexts (extreme pluralism), or do they travel with us across contexts (modest pluralism)?

Glasgow argues that constructionism only gives us reason to accept modest ontological pluralism. That is, social constructionism about gender does not give

63. Glasgow (2007), 560-61. Glasgow uses the language of 'ontological localism', rather than 'ontological pluralism', and 'concepts' rather than 'kinds'. However, Glasgow's ontological localism is a version of pluralism, and the term 'concepts' is used to pick out social kinds.

64. Of course, someone may have no place at all within a given set of operative gender kinds, as I've argued is sometimes the case for nonbinary persons within dominant contexts.

65. Does this view amount to gender kinds like woman or man being like rich or tall, where they are single kinds with context variant standards? While I cannot defend this claim fully here, it is important to recognize that the number, membership conditions, and social significance of particular gender kinds varies across contexts. Given this, it is hard to see how there could be a single set of operative gender kinds, differing only in contextual standards. Thanks to Mike Rea for raising this worry. 
us reason to think that someone's gender changes across contexts. Gender kinds are socially constructed; this doesn't mean one must be at the site of a kind's construction in order to belong to that kind. Gender constructionism simply gives us reason to think that there isn't a "location independent standard" by which one's gender is determined.$^{66}$ One can have multiple genders, all of which are indexed to various gender kinds, many of which may not operate in one's immediate context.

This modest ontological pluralism about gender is enough to secure veridicality (even if not social intelligibility) for trans and nonbinary identities within dominant contexts. Suppose that someone is a woman relative to dominant gender kinds, but a man relative to trans-inclusive gender kinds. According to modest ontological pluralism, this person has both of these gender kind memberships in all contexts. For this reason he can truthfully say, "I am a man." 67 This is because the term 'man' in his claim refers to the trans-inclusive gender kind-a kind he retains membership in even when in contexts where this kind is not operative. ${ }^{68}$

At this point, one might worry that there is a lurking tension between my claim that dominant contexts have oppressive operative gender kinds, and my claim that trans persons' gender identities are veridical even in dominant contexts. ${ }^{69}$ Where is the oppression, one might wonder, if not in undermining trans identities? It is tempting to think that, if trans identities are veridical in dominant contexts, these contexts aren't so oppressive after all.

In response, first recall that the source of oppression, in cases of ontological oppression, lies in unjustly constraining people's behavior, thought, or affect on the basis of their group membership. Even though trans identities always are veridical due to trans-inclusive gender kinds, dominant gender kinds remain oppressive in this sense. Because the operating gender kinds marginalize and exclude trans and nonbinary persons, their identities are frequently rejected or unintelligible within dominant contexts. They fail to carry the social meaning that they do in transinclusive contexts, because they are grounded in gender kinds that do not operate in dominant contexts. In short, trans and nonbinary identities are veridical, but socially distorted, unintelligible, or erased. ${ }^{70}$ As a result, trans persons unwillingly

66. Glasgow (2007), 561. Brian Epstein (2014) makes a very similar point, arguing that we must distinguish contexts of construction and contexts of instantiation. Once we've done so, we can "look for baristas in the Ottoman Empire or in 17th century England," even though this kind arguably was constructed in the twentieth century. Glasgow and Epstein (rightly, I think) depart from the view of social ontology sometimes suggested in Foucault-i.e., that social properties and kinds can be instantiated only within their context of construction.

67. Glasgow (2007) argues the same with respect to race. Someone who is New-Orleans-Black, "when asked, can answer truthfully when she says 'No, I would still be [black] if I went to Brazil.”

68. This position is compatible with a mainstream externalist semantics about gender terms like 'man'. This is because someone's linguistic community-here, trans-inclusive communities-uses the term 'man' in a way that includes this person in its extension. The meanings of gender terms 'ain't just in the head', but they are portable.

69. Thanks to Lori Watson for raising this worry.

70. Of course, pejorative social meanings imposed upon trans and nonbinary identities are salient (and devastating). 
are understood by others in terms of dominant gender kinds, and the unwanted roles, norms, and expectations that accompany them.

While this view can explain why trans identities are veridical in dominant contexts without undermining the injustice of dominant gender kinds, two apparent costs remain. First, it is possible that there are gender identities that do not correspond to any gender kinds. Modest ontological pluralism, on which gender kinds are social and not merely psychological phenomena, cannot provide an ontological basis for these identities. However, even nonveridical identities can be important in effecting change to bring about new gender kinds. Identifying as having a gender that does not yet exist, even when these claims are false and largely unintelligible, can be a way to advocate for the construction of new gender kinds. (I suspect that, historically, trans and nonbinary identities have had this effect. More on this in 4.2.)

Second, modest ontological pluralism implies that those whose gender terms track trans-exclusive gender kinds speak truly when they say, e.g., "Trans men are not men," or otherwise refuse to classify trans men as men. This is because, even while a trans man belongs to the trans-inclusive kind man, he does not fall within the trans-exclusive kind man. And this latter kind is the one typically picked out by 'men' when those in dominant contexts say, e.g." "Trans men are not men."

Admitting that trans-exclusive classifications can be true might seem like a significant cost of modest ontological pluralism. But I actually think it is a virtue. Historical examples abound of assertions that were true because of pernicious social kinds. In the nineteenth century, speakers in the United States could truly claim, "Women cannot vote," or "This slave is my property." Hindsight tells us not that these claims were false, but that they were wrong. Similarly, when we take the possibility of gender-related ontological oppression seriously, we should expect that there are many true gender classifications that are true because of oppressive gender kinds. Or, to approach this point from a slightly different angle, even if speakers in trans-exclusive contexts get an individual's gender metaphysically correct (relative to the operative kinds), they still get gender writ large normatively wrong. To return full circle, this is why the Real Gender assumption fails: tracking operative gender kinds is cheap, and can reinforce oppression. The interesting and important project, to my mind, is not asking whether a gender classification is true. Rather, it is determining what gender kinds operate in a social context, and evaluating their relationship to social power and privilege-a topic I'll return to in section 4.3.

\subsection{WHAT ABOUT BELIEF?}

Admitting that trans-exclusive gender classifications can be true raises a further worry: what about belief? In particular, one might worry that, in rejecting the Real Gender assumption, I am advising those in dominant contexts to treat transinclusive classifications as true but believe that they are false. That is, it seems I am advising those in dominant contexts to treat trans men as if they did in fact belong 
to the dominant gender kind men, even though I've also argued that they are, at most, marginal members of this kind. Such classifications seem akin to 'noble lies'. At worst, to endorse these noble lies seems to undercut or infantilize trans identities. At best, it endorses cognitive incoherence, advocating both assertion and disbelief of trans-inclusive gender classifications. ${ }^{71}$ Perhaps we should prefer a theory on which everyone, regardless of the operative kinds, should believe that (and not only act as if) trans-inclusive classifications are true. ${ }^{72}$

Happily, there are at least two ways to avoid the 'noble lie' worry, one more controversial than the other. I will discuss both in turn. The first, less controversial solution, preserves a standard truth-norm on belief. On this solution, those in dominant contexts should believe both that trans men are not men relative to the trans-exclusive kind and that trans men are men relative to the trans-inclusive kind. However, they should classify persons on the basis of the trans-inclusive kind. On the second, more controversial solution, we move to a broader notion of the norms governing belief, such that that those in dominant contexts should believe that trans men are men even relative to the trans-exclusive kind.

\subsubsection{Maintaining a Truth-Norm on Belief}

The first solution is, on its face, fairly straightforward. Recall my earlier argument for modest ontological pluralism, and the idea that someone has multiple gender kind memberships, even when many of those kind are not operative in the immediate contexts. Given this, we can distinguish between two propositions that someone within a dominant context might pick out when they assert, "Chris (a trans man) is a man": ${ }^{73}$
(a) $<$ Chris is a $\operatorname{man}_{\text {dominant-kind }}>$
(b) $<$ Chris is a $\operatorname{man}_{\text {trans-inclusive-kind }}>$

So long as this person can refer to a trans-inclusive kind even while in a dominant context, their assertion can pick out (b). In that case, even assuming a truth-norm on belief, those within a dominant context should believe that the assertion "Chris is a man" is true. After all, proposition (b) is true.

This might seem like a sleight of hand. Yes, proposition (b) is true, but so is the negation of (a). One might worry I've pushed the problem a step back. Perhaps those in dominant contexts should believe (b), but assuming a truthnorm on belief, they also should believe the negation of (a). That is, they should believe that the assertion "Chris is a man" is true when it picks out (b); but they

71. One might here think of claims like, "It is raining, but I do not believe it is raining." Shah and Velleman (2005), 497, for example, argue that claims like this are incoherent because "the deliberative question whether to believe that $\mathrm{p}$ is transparent to the question whether p."

72. Thanks to Zoe Johnson King and Elizabeth Barnes for raising this worry.

73. While gender classifications happen in many ways, verbal classification is the clearest for discussing the issue of belief. 
also should believe that the assertion "Chris is not a man" is true when it picks out the negation of (a).

Supposing this is the case-and I lean toward thinking it is-then the more pressing question becomes one of action. Which belief should guide classification practices? That is, since those in dominant contexts should believe both (b) and the negation of (a), how should they classify Chris's gender? Which assertion should they make? How should they treat Chris? If they classify Chris according

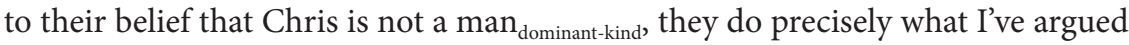
should be avoided-they reinforce an oppressive gender kind. And yet, if they

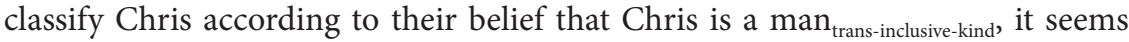
they are doomed to fall into verbal disputes or crosstalk with those around them, who use terms like 'man' to refer to the operative kind, $\operatorname{man}_{\text {dominant-kind }}$ In other words, we might worry that someone in a dominant context will 'talk past' others if they classify Chris according to trans-inclusive kinds, given that others in their context use the word 'man' to pick out man $_{\text {dominant-kind. }}$.

Thankfully, the dichotomy between reinforcing ontological oppression and mere 'talking past' is a false one. To see why, we must first recognize that gender classifications are not simply descriptive: they have further consequences ${ }^{74}$ such as applying or enabling gendered constraints, expectations, obligations, and permissions. Moreover, many of these social consequences accompanying gender classifications remain constant across contexts. For example, when someone asserts 'Chris is a man', their use of the term 'man' conveys a rich body of cultural, emotional, and political associations - associations that are salient even when they use 'man' in a way that diverges from standard use in the context of utterance. David Plunkett describes such terms as ones where the "associations will often be harder to shake than the specific application-conditions associated with the term itself, or the specific meaning it has at a given time." 75 That is, words like 'woman' and 'man', like 'freedom' or 'person', have robust associations that-to some extent-remain constant across different referents.

Recognizing this feature of gender classifications reveals two reasons why someone who classifies Chris as a man, even within a dominant context, is not doomed to meaningless 'talking past'. First, when people use terms like 'man' differently, they often engage in substantive disagreement about who ought to have the robust associations welded to that particular gender classification. ${ }^{76}$ Even if two people use the same word ('man') to pick out different gender kinds, and respectively claim that Chris is a $\operatorname{man}_{\text {trans-inclusive-kind }}$ and is not a man dominant-kind $_{\text {, }}$ their dispute is not merely verbal. They disagree about whether Chris-and people like

74. In the case of speech acts of classification, these would be the 'perlocutionary' effects of classification.

75. Plunkett (2015), 843.

76. Plunkett (2015) calls this a 'metalinguistic negotiation', and describes it as a dispute over what concept should be employed by a term. Because I think the concepts are important only because of the kinds they pick out, I frame this point in terms of the kind referents, rather than concepts. 
Chris-should be conferred the social associations that come with being classified as a man in the immediate context.

Second, when someone in a dominant context eschews the operative gender kinds, and instead classifies gender according to trans-inclusive kinds, they implicitly provide an internal critique of the ideology that sustains dominant gender kinds. More specifically, they imply that dominant gender kinds-despite a pervasive myth of their universality and immutability-are contingent and malleable. They could have been or could become otherwise.

For both of these reasons, disagreements about who (if anyone) ought to be classified as a man, woman, or nonbinary (among others), and which kinds (if any) gender terms should refer to, are neither trivial nor merely verbal. These disputes are substantive and normative; they impact classification practices, and with them, the operative gender kinds.

\subsubsection{Alternatives to a Truth-Norm on Belief}

The second and more controversial solution targets those who are committed to the idea that those in dominant contexts ought to believe that a trans man is a man full stop, even relative to the operative gender kinds. The view I've described implies that it is at least possible and in fact likely that dominant gender kinds marginalize or exclude trans and nonbinary identities. If this is right, the combination of these views means that those in dominant contexts not only ought to make trans-inclusive classifications, but also ought to believe these classifications even when they are unsupported by available evidence.

While controversial, this view is not without merit. ${ }^{77}$ In recent work, epistemologists have argued that non-truth-tracking reasons bear on whether or not to believe a proposition. For example, Rima Basu argues that "people wrong others in virtue of what they believe about them, and not just in virtue of what they do." ${ }^{78}$ According to Basu, morality sometimes gives us a duty to believe against our evidence, especially in cases where we have reason to suspect our cognitive frameworks are influenced by prejudice. If Basu is correct, and epistemic and moral norms are sometimes inseparable in this way, then similarly we might suspect that one ought to believe trans-inclusive gender classifications are true, even if we have evidence that they are false. It might be wrong, in other words, to believe that trans-inclusive classifications are false, as well as to act as if they were false.

In a similar vein, but emphasizing rationality rather than morality, Rinard (2017) argues that the rationality of belief is no different from the rationality of other states. Just as nonevidential considerations (e.g., of prudence or morality) can provide reasons to take an action, or adopt an intension, Rinard argues that they also can provide reasons to adopt a belief (e.g., as in Pascalian cases). If Rinard is right, then the fact that it would be politically and morally best to

77. Thanks to Dan Greco for helpful discussion.

78. Basu (forthcoming). 
believe trans-inclusive gender classifications is just as much a reason to adopt those beliefs as the fact that they are supported by one's evidence. It might be rational to believe that trans-inclusive classifications are true, even if one has evidence that they are false.

Finally, and somewhat along Rinard's lines, one might think that even if rational belief concerns epistemic rationality specifically, this rationality must be more holistic than merely tracking evidential support for a specific classification. ${ }^{79}$ If accurately tracking (and thus maintaining) trans-exclusive gender kinds means that trans persons and their experiences are not intelligible, and knowledge about them is precluded, then these practices are epistemically failing in a larger sense. Why should rationality concern tracking evidential support for a given claim, but not gaining fuller understanding of social phenomena and other persons? ${ }^{80}$ Here again, believing trans-inclusive gender classifications are true may be rational even in the face of contrary evidence, because it moves toward filling a large hermeneutical gap. ${ }^{81}$

\subsection{METHODOLOGICAL UPSHOTS}

In closing, I want to flag methodological upshots of my view. As noted earlier, although gender kinds are widely taken to be socially constructed, many metaphysicians frame gender kinds as operative across all contexts, or at least fail to specify which gender kinds are under consideration. One result is a tendency to model trans-inclusive gender kinds as though they operated in dominant contexts. The motivation for doing so is admirable, but this tendency risks overlooking ontological oppression. If we aim to analyze the kinds operating in dominant contexts, we should be prepared to find unjust gender kinds-kinds that are illegitimate on a variety of grounds, but nevertheless obtain. ${ }^{82}$

Historically, revealing oppressive gender kinds has been the task of feminist metaphysics. ${ }^{83}$ The rising influence of trans-inclusive communities has brought to

79. Here I draw from Quine's (1951) picture of a web of belief, in which experience underdetermines our conceptual systems, but in which these systems can be modified in better or worse ways to reduce conflict with experience.

80. Jose Medina (2012) argues that this kind of ignorance among privileged persons with respect to oppressed groups protects their privilege by masking insensitivities and prejudices.

81. Here, someone might have the same worry as in 4.2.1: What good can it do to make false classifications, even when based on rational (or moral) beliefs? My response is the same. False gender classifications are part of substantive, normative disputes over what gender classification practices ought to be, even if they are descriptively incorrect about what these practices already are.

82. Their illegitimacy, in my view, stems from not only their injustice, but also their basis in a gender ideology ridden with false beliefs about the 'naturalness' of binary gender kinds, not to mention an assumed 'natural' relationship between natal genitalia and persons' psychologies, personalities, and social roles.

83. Simone de Beauvoir, Monique Wittig, Judith Butler, Catharine MacKinnon, Sally Haslanger, and others described dominant gender kinds in material terms: hierarchical, binary, oppressive, heterosexist, self-reinforcing, and caught up in economic, racist, and other oppressive systems. 
philosophy a new impulse: theorize trans-inclusive gender kinds. This impulse is a good one. However, this theorizing is often presented in one of two ways. The first is to describe trans-inclusive gender kinds as though they are the only gender kinds, operating even within dominant contexts. ${ }^{84}$ The second is to describe transinclusive concepts or semantics, and to contrast these with 'material' gender kinds, which are taken to be binary and heterosexist. ${ }^{85}$ Either use of an otherwise helpful impulse is, I think, dangerous on at least two counts.

First, these approaches risk getting gender phenomena wrong and, in so doing, entrenching an unproductive ideological divide. While the first ignores transexclusionary gender kinds altogether, the second ignores the extent to which gendered material realities and gender concepts and semantics are mutually reinforcing. Trans-exclusive concepts uphold and are upheld by trans-exclusive structures and practices. As a result, either approach suggests that those in dominant contexts are radically ignorant about their operative gender kinds. More particularly, they at least appear to say that the gender concepts and semantics many people have used throughout their lives are as illegitimate as phlogiston or unicorns. Unsurprisingly, the backlash to this (at least perceived) suggestion writes off gender theories as products of ivory tower elitism.

Second, these theoretical approaches camouflage, rather than illuminate, the structures and practices that threaten trans and gender nonconforming bodies every day. Materialist feminist history emphasizes how sex, sexuality, and gender are constrained and even defined by heteropatriarchal institutions. And while feminist metaphysics should not solely focus on these institutions, it also should not ignore them, instead describing gender kinds that presumably would operate in (more) just contexts.

Metaphysics is big enough for all of us. Certainly, it is big enough for theories of the gender kinds that operate in dominant as well as trans-friendly contexts, not to mention many other contexts. But one should not expect to find ideal gender kinds. Even in trans-friendly spaces, inflections of race, ability, class, and sexuality construct gender kinds that marginalize or fail to recognize certain groups. A central task of feminist philosophy is, I take it, to model gender kinds while illuminating their relationships to power and privilege, rather than to theorize about presumptively ideal gender kinds. ${ }^{86}$

84. See, e.g., McKitrick (2015).

85. See, e.g., Jenkins (2015).

86. In this respect, I take my methodology to align with Sally Haslanger's (2000) notion of the 'ameliorative project'. For Haslanger, an ameliorative project in feminist metaphysics requires that one look at the world to see how a given social kind functions-i.e., what social work it doesand then model this kind in a way that is conducive for social justice projects. In the case of oppressive social kinds, for example, ameliorative projects would reveal the oppressive natures of these kinds. While I agree with Haslanger, I additionally emphasize a focus on the contextspecificity of social kinds. See Barnes (2020) for more on various approaches to the ameliorative project. 
With this mindset, I trust it will become even clearer why we must reject the Real Gender assumption. This assumption does not challenge, but reinforces existent power. I propose a pluralistic turn to empirically informed theorizing about the many gender kinds that operate across various contexts. The Real Gender assumption should not settle the future of gender kinds, dominant or otherwise. But this doesn't mean we have nowhere to look.

\section{ACKNOWLEDGMENTS}

Many thanks to Elizabeth Barnes, Shamik Dasgupta, Dan Greco, Rafeeq Hasan, Katharine Jenkins, Zoe Johnson King, Joanna Lawson, Laurie Paul, Cat Saint-Croix, Keyvan Shafiei, Lori Watson, and audiences at the Pacific APA, UNC Asheville, Wayne State, and Princeton for feedback on earlier versions of this paper.

\section{REFERENCES}

Ásta. 2011. “The Metaphysics of Sex and Gender." In Feminist Metaphysics, edited by Charlotte Witt. New York: Springer.

Bach, T. 2012. "Gender Is a Natural Kind with a Historical Essence." Ethics 122(2): 231-72.

Barnes, E. 2016. "Realism and Social Structure." Philosophical Studies. 174 (10), 2417-2433.

Barnes, E. 2019. "Gender and Gender Terms 1." Nous 54(3): 704-730.

Barnes, E. 2020. "Feminist Metametaphysics." Routledge Companion to Metametaphysics, eds. Ricki Bliss.

Basu, R. 2018. “The Wrongs of Racist Beliefs.” Philosophical Studies 176: 2497-2515.

Bettcher, T. 2009. “Trans Identities and First-Person Authority." In You've Changed: Sex Reassignment and Personal Identity, edited by Laurie Shrage. Oxford University Press.

Bettcher, T. 2013. “Trans Women and the Meaning of 'Woman." In Philosophy of Sex: Contemporary Readings, edited by A. Soble, N. Power, and R. Halwani, 233-50. 6th ed. Rowman \& Littlefield. 233-50.

Bettcher, T. 2014. "Trapped in the Wrong Theory: Rethinking Trans Oppression and Resistance." Signs: Journal of Women in Context and Society 39(2).

Bornstein, K. 1994. Gender Outlaw: On Men, Women, and the Rest of Us. London: Routledge.

Bradford, N., G. Rider, J. Catalpa, Q. Morrow, D. Berg, K. Spencer, and J. McGuire. 2018.

"Creating Gender: A Thematic Analysis of Genderqueer Narratives." International Journal of Transgenderism. DOI: 10.1080/15532739.2018.1474516.

Brubaker, R. 2016. “The Dolezal Affair: Race, Gender, and the Micropolitics of Identity." Ethnic and Racial Studies 39(3): 414-49.

Chambers, C. 2017. Against Marriage: An Egalitarian Defense of the Marriage-Free State. Oxford: Oxford University Press.

"Charlotte City Council Approves LGBT Protections in 7-4 Vote." 2016, February 22. Charlotte Observer. URL: http://www.charlotteobserver.com/news/politics-government/article61786967.html.

Clark, J. (2019) "They, Them, and Theirs." Harvard Law Review 132, No. 18-61.

Dembroff, R. 2017. “Ontological Oppression." Categories We (Aim to) Live By. Dissertation, Princeton University.

Dembroff, R. 2020. "Beyond Binary: Genderqueer as Critical Gender Kind." Philosopher's Imprint 20(9): 23.

Dembroff, Robin, and Cat Saint-Croix. 2019. "Yep, I’m Gay: Understanding Agential Identity." Ergo: An Open Access Journal of Philosophy 6(20).

Dotson, K. 2012. "How Is This Paper Philosophy?" Comparative Philosophy 3(1): 3-29. 
Eckstein, R., D. Moss, and K. Delaney. 2010. “Sports Sociology's Still Untapped Potential.” Sociological Forum 25(3): 500-518. Retrieved from http://www.jstor.org/stable/40783513.

Epstein, B. 2014. "How Many Kinds of Glue Hold the Social World Together?" In Perspectives on Social Ontology and Social Cognition, edited by Mattie Galloti and John Michael. Dordrecht: Springer.

Epstein, D. 2014. The Sports Gene: Inside the Science of Extraordinary Athletic Performance. New York: Penguin.

Foucault, M. 1978. The History of Sexuality, vol. 1. New York: Vintage.

George, B. R., and R. A. Briggs. manuscript. "Science Fiction Double Feature: Trans Liberation on Twin Earth."

Glasgow, J. 2007. “Three Things Constructionism about Race Can Do." Journal of Social Philosophy 38(4): 554-68.

Green, E., K. Benner, and R. Pear. 2018, October 21. “'Transgender' Could Be Defined out of Existence under Trump Administration.” New York Times. https://www.nytimes.com/2018/10/21/us/politics /transgender-trump-administration-sex-definition.html.

Guttmann, A. 1991. Women's Sports: A History. New York: Columbia University Press.

Hacking, I. 1999. The Social Construction of What? Cambridge, MA: Harvard University Press.

Haslanger, S. 1995. “Ontology and Social Construction.” Philosophical Topics 23(2): 95-125.

Haslanger, S. 2000. "Gender and Race: (What) Are They? (What) Do We Want Them to Be?" Noûs 34(1): 31-55.

Haslanger, Sally (2007). "But mom, crop-tops are cute!" Social knowledge, social structure and ideology critique. Philosophical Issues 17 (1):70-91.

Haslanger, S. 2016. What is (social) structural explanation? Philosophical Studies 173: 113-130.

Haslanger, Sally. 2018. "Social Explanation: Structures, Stories, and Ontology. A Reply to Díaz León, Saul, and Sterken." Disputatio 10(50): 245-273.

Ivy, V. 2013. “The Supportive Reasons Norm of Assertion.” American Philosophical Quarterly 50(2): 121-35.

Ivy, V. 2015. “Trans`Formative Experiences.” Res Philosophica 92(2): 419-40.

Jenkins, K. 2015. "Amelioration and Inclusion: Gender Identity and the Concept of Woman." Ethics 126(2): 394-421.

Jenkins, K. 2016. “Ontic Injustice.” Dissertation thesis, The University of Sheffield.

Knight, C., and K. Wilson. 2016. "Transgendered People in the Criminal Justice System.” In Lesbian, Gay, Bisexual and Trans People (LGBT) and the Criminal Justice System, edited by Charlotte Knight and Kath Wilson London: Palgrave Macmillan.

Koyama, E. 2006. “Whose Feminism Is It Anyway?” In The Transgender Studies Reader, edited by Susan Stryker and Stephen Whitter. London: Routledge.

MacKinnon, C. 2015. "Harm Is Harm, Hello." Interview with On Century Avenue. URL = http:// oncenturyavenue.org/2015/03/harm-is-harm-hello/. Accessed May 8, 2017.

MacKinnon, C. 1989. Toward a Feminist Theory of the State. Cambridge, MA: Harvard University Press.

MacGinty, R. 2015. "Where Is the Local? Critical Localism and Peacebuilding." Third World Quarterly 36(5): 840-56.

Mallon, R. 2004. "Passing, Traveling and Reality: Social Constructionism and the Metaphysics of Race." Nô̂s 38 (4): 644-673

Mallon, R. 2016. The Construction of Human Kinds. Oxford: Oxford University Press.

Marcus, N. C. 2018. "The Global Problem of Bisexual Erasure in Litigation and Jurisprudence." Journal of Bisexuality 18(1): 67-85.

McKitrick, J. 2015. “A Dispositional Account of Gender.” Philosophical Studies 172(10): 2575-89.

McQueen, P. 2016. "Post-identity Politics and the Social Weightlessness of Radical Gender Theory." Thesis Eleven 134(1): 73-78.

Medina J. 2012. "Hermeneutical Injustice and Polyphonic Contextualism: Social Silences and Shared Hermeneutical Responsibilities." Social Epistemology 26(2): 201-20.

Mikkola, M. 2016. The Wrong of Injustice: Dehumanization and Its Role in Feminist Philosophy. Oxford: Oxford University Press.

Mikkola, M. 2011. “Ontological Commitments, Sex, and Gender." In Feminist Metaphysics, edited by Charlotte Witt. New York: Springer.

Molina, N. 2014. How Race Is Made in America: Immigration, Citizenship, and the Historical Power of Racial Scripts (Vol. 38). Berkeley: University of California Press. 
National Center for Transgender Equality. 2018. “International." URL: https://transequality.org/issues /international. Accessed Nov. 9, 2018.

National Center for Transgender Equality. 2016. "U.S. Transgender Survey: Executive Summary." URL: https://transequality.org/sites/default/files/docs/usts/USTS-Executive-Summary-Dec17 .pdf. Accessed November 9, 2018.

Nestle, J., R. A. Wilchins, and C. Howell. 2002. GenderQueer: Voices from beyond the Sexual Binary. Los Angeles: Alyson Publications.

O'Connor, C. 2019. The Origins of Unfairness. Oxford: Oxford University Press.

Plunkett, D. 2015. "Which Concepts Should We Use?: Metalinguistic Negotiations and the Methodology of Philosophy." Inquiry 58(7-8): 828-74.

Quine, W. V. O. 1951. “Two Dogmas of Empiricism.” Philosophical Review 60(1): 20-43.

Rinard, S. 2017. "No Exception for Belief." Philosophy and Phenomenological Research 94(1): 121-43.

Risman, B. 2018. Where the Millenials Will Take Us: A New Generation Wrestles with the Gender Structure. Oxford: Oxford University Press.

Rivers, D. 2015. Radical Relations: Lesbian Mothers, Gay Fathers, and Their Children in the United States since World War II. Chapel Hill: University of North Carolina Press.

Roen, K. 2001. “Transgender Theory and Embodiment: The Risk of Racial Marginalisation.” Journal of Gender Studies 10(3): 253-63.

Root, M. 2000 "How We Divide the World" Philosophy of Science (67) Supplement. Proceedings of the 1998 Biennial Meetings of the Philosophy of Science Association. Part II: Symposia Papers: S628-S639.

Saul, J. 2013. "Politically Significant Terms and Philosophy of Language." In Out from the Shadows: Analytical Feminist Contributions to Traditional Philosophy, edited by S. Crasnow and A. Superson. Oxford: Oxford University Press.

Scheman, N. 2011. "Queering the Center by Centering the Queer: Reflections on Transsexuals and Secular Jews." In Shifting Ground: Knowledge and Reality, Transgression and Trustworthiness, edited by Naomi Scheman. Oxford: Oxford University Press.

Shah, N., and J. D. Velleman. 2005. "Doxastic Deliberation." Philosophical Review 114(4): 497-534.

Spade, D. 2015. Normal Life: Administrative Violence, Critical Trans Politics, and the Limits of Law. Durham, NC: Duke University Press.

Stanley, E., and N. Smith, eds. 2011. Captive Genders: Trans Embodiment and the Prison Industrial Complex. Oakland: AK Press.

Steensma, T., B. Kreukels, A. de Vries, and P. Cohen-Kettenis. 2013. "Gender Identity Development in Adolescence." Hormones and Behavior 64(2): 288-97.

Stone, S. 1992. “The Empire Strikes Back: A Posttranssexual Manifesto.” Camera Obscura 10 (2): 150-76.

Stryker, S. 2008. Transgender History. Berekely: Seal Press.

Williams, C. 2015. "Sex, Gender, and Sexuality: The TransAdvocate interviews Catharine A. MacKinnon.” TransAdvocate. URL: https://www.transadvocate.com/sex-gender-and-sexuality -the-transadvocate-interviews-catharine-a-mackinnon_n_15037.htm. Accessed November 9, 2018 .

Yoshino, K. 2000. “The Epistemic Contract of Bisexual Erasure." Stanford Law Review 52(2): 353-461. doi: $10.2307 / 1229482$.

Young, I. M. 2013. "Five Faces of Oppression.” In The Community Development Reader, edited by James DeFilippis and Susan Saegart. London: Routledge. 346-55. 